\title{
PEMETAAN POTENSI PEMUTIHAN KARANG DI PERAIRAN INDONESIA MENGGUNAKAN ANALISIS DATA SUHU PERMUKAAN LAUT
}

\author{
Dany Pangestu ${ }^{1}$, Ratih Suci Ramadhanti ${ }^{2}$, Ahmad Fadlan ${ }^{3}$ \\ Sekolah Tinggi Meteorologi Klimatologi dan Geofisika \\ Jl Perhubungan 1 no 5 Pondok Betung Pondok Aren Tangerang Selatan \\ Email : ratihfabra@gmail.com
}

\begin{abstract}
Indonesia is the country that contributed the largest coral reefs, about 18\% total of entire the world. Area of coral reef in Indonesia known as the "Coral Triangle". This ecosystem has high ecology and economic value. The existence of the coral reefs are the main attraction for tourism destination. However, the function and role of these ecosystems is decreasing due to natural factors and artificial factors. One of the natural factor is due to the influence of global warming, such as sea surface temperature (SST), causing damage and coral death, known as coral bleaching. The purpose of this study was to identify the potential for coral bleaching in Indonesian waters using SPL anomaly analysis obtained from monthly AVHRR POES in the morning and night. This research used hotspots data (HS) by calculating the average of data anomaly difference with a maximum monthly average data during 10 years (2006 - 2017). The results obtained show that areas that have the potential to become coral bleaching in Indonesian waters are quite varied. In general, it covers the northern coast of Banten, DKI Jakarta, West Java, Central Java, East Java, the northwest coast of Lampung, Pekanbaru and Riau, the northwest coast of Papua Island, and North Natuna waters. The results also showed that sea surface temperatures in Indonesian waters were quite influential on coral bleaching.
\end{abstract}

Keywords: Hotspot, Mapping, Coral Bleaching, Indonesian Water, SST, POES AVHRR

\begin{abstract}
Abstrak: Indonesia merupakan negara penyumbang terumbu karang terbesar yaitu $18 \%$ dari total dunia. Wilayah terumbu karang di Indonesia dikenal dengan wilayah "Coral Triangle". Ekosistem ini memiliki nilai ekologis dan ekonomis yang tinggi. Keberadaanya merupakan daya tarik tersendiri untuk dijadikan lokasi wisata. Namun, fungsi dan peranan ekosistem ini menurun akibat faktor alam dan faktor buatan. Salah satu faktor alamnya diakibatkan pengaruh pemanasan global yaitu naiknya suhu permukaan laut (SPL) sehingga menyebabkan kerusakan dan kematian karang atau dikenal sebagai pemutihan karang. Tujuan penelitian ini adalah mengidentifikasi potensi terjadi pemutihan karang di wilayah perairan Indonesia menggunakan analisis anomali SPLyang diperoleh dari POES AVHRR pagi dan malam bulanan. Metode yang diugunakan mencari data hotspot (HS) dengan melakukan perhitungan rata rata selisih data anomali dengan data rata rata maksimum bulanan selama 10 tahun (2006 - 2017). Hasil yang didapat menunjukkan bahwa wilayah yang berpotensi menjadi pemutihan karang di perairan Indonesia cukup beravariasi. Secara umum meliputi meliputi pesisir utara dari Provinsi Banten, DKI Jakarta, Jawa Barat, Jawa Tengah, Jawa Timur, pesisir barat laut Lampung ,Pekanbaru dan Riau, pesisir barat laut dari Pulau Papua, dan perairan Natuna Utara. Hasil penelitian juga menunjukkan bahwa suhu permukaan laut di perairan Indonesia cukup mempengaruhi pemutihan karang
\end{abstract}

Kata kunci: Hotspot, Pemetaan, Pemutihan Karang, Perairan Indonesia, SPL, POES AVHRR, 


\section{PENDAHULUAN}

\subsection{Latar Belakang}

Sebagai negara kepulauan terbesar di dunia, Indonesia telah diakui secara internasional berdasarkan United Nations Convention on the Law of the Sea (UNCLOS) 1982 yang kemudian diratifikasi oleh Indonesia dengan Undang-Undang No. 17 Tahun 1985. Hal tersebut dikarenakan dua pertiga wilayah Indonesia terdiri dari laut dengan panjang garis pantai mencapai $95.161 \mathrm{~km}$, terpanjang kedua setelah Kanada (Wirawan, 2017).

Wilayah tepian pulau yang dikenal sebagai wilayah pesisir merupakan salah satu wilayah yang mempunyai potensi besar untuk lebih dikembangkan secara terpadu (Integrated Coastal Zone Management - ICZM), namun perlu dijaga kelestarian lingkungannya lebih awal agar fenomena alam yang mempengaruhinya dapat dipantau sedini mungkin (Supriharyono, 2000). Salah satu gejala atau fenomena alam yang dominan mempengaruhi perubahan parameter wilayah pesisir dan pulau-pulau kecil adalah pengamatan parameter meteorologi maritim.

Meteorologi maritim merupakan ilmu terapan yang menggunakan pendekatan fisika atmosfir serta kaitannya dengan perubahan kondisi paremeter oseanografi dan dinamika perairan pantai termasuk, suhu air laut, gelombang laut, arus laut permukaan. Menurut Gordon (1996) Salah satu fenomena meteorologi yang cukup unik namun erat kaitannya dengan meteorologi maritim adalah korelasi curah hujan terhadap kondisi arus laut serta suhu permukaan laut (SPL).

Indonesia merupakan negara yang memiliki keanekaragaman sumberdaya alam dan sumberdaya manusia yang melimpah. Sumberdaya alam yang terdapat di Indonesia berupa mineral, flora, fauna, iklim, dan sebagainya. Keberagaman potensi wilayah tersebut dapat dijadikan sebagai modal utama dalam pengembangan pariwisata di Indonesia.

Pariwisata menjadi salah satu sektor terbesar pemasukan sumber pendapatan negara atau daerah. Hal tersebut akan meningkatkan kesejahteraan masyarakat dan menjadi lahan penanaman modal asing atau investor lokal. Pada hakikatnya seharusnya semakin banyaknya sumberdaya maka potensi pariwisata semakin tinggi sehingga idealnya masyarakat lebih makmur dan sejahtera. Akan tetapi, di Indonesia banyak potensi sumberdaya yang dikembangkan sebagai pariwisata tetapi justru tidak berdampak terhadap kesejahteraan masyarakat Indonesia secara keseluruhan. Penelitian ini dilakukan untuk mengetahui bagaimana persebaran pemutihan karang di wilayah perairan Indonesia.

\subsection{Tujuan}

Secara lebih spesifik tujuan dari penelitian ini diantaranya adalah sebagai berikut:

1. Mengidentifikasi wilayah terjadi potensi pemutihanan karang di perairan Indonesia.

2. Menganalisis wilayah potensi pemutihan karang terhadap objek wisata di Indonesia

\section{METODOLOGI PENELITIAN}

\subsection{Objek Penelitian}

Pada penelitian ini peneliti ingin mengetahui wilayah yang berpotensi menjadi pemutihan karang di perairan Indonesia berdasarkan tinjauan suhu permukaan laut. Indonesia merupakan negara tropis yang berada pada $6{ }^{0} \mathrm{LU}-11{ }^{0} \mathrm{LS}, 95{ }^{\circ} \mathrm{BT}-141{ }^{0} \mathrm{BT}$. Wilayahnya yang terletak diantara Samudera Hindia dan Samudera Pasifik serta Benua Asia dan Australia membuat kawasan Indonesia rentan terhadap perubahan unsur-unsur atmosfer. 


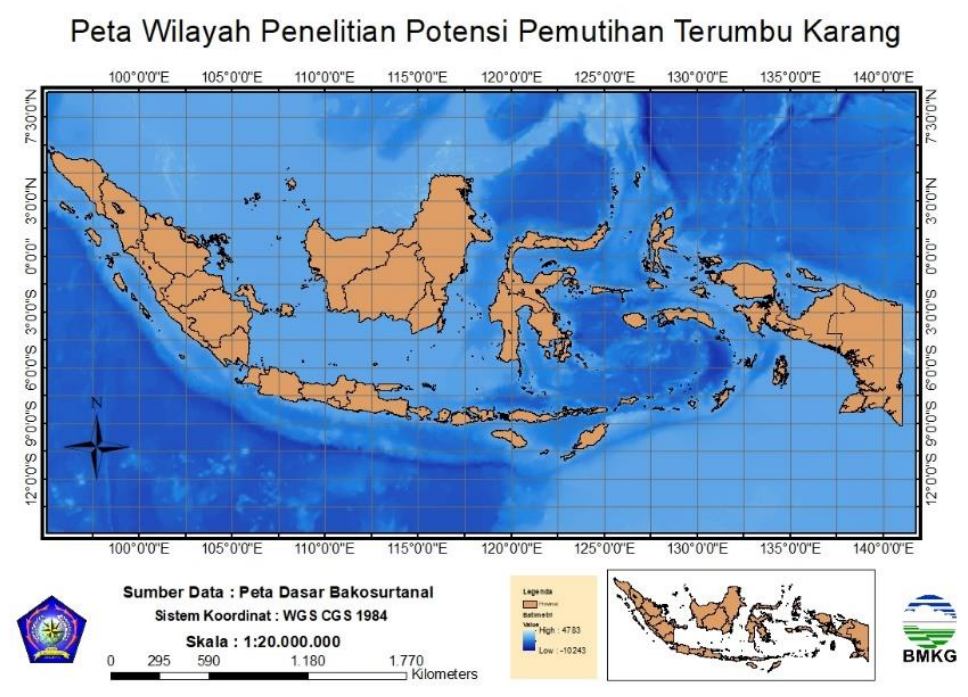

Gambar 3.1 Peta Wilayah Penelitian

\subsection{Sumber Penulisan}

Sumber Penulisan atau sumber gagasan penyusunan karya ilmiah yang dimaksud adalah bahan penulisan. Bahan penulisan adalah berbagai informasi dapat diperoleh dari inferensi atau pengalaman, observasi, deduksi dari suatu teori, kebijakan-kebijakan, dan laporan penelitian. Karya ilmiah ini sumber penelitian diperoleh dari observasi, observasi yang dimaksud adalah pengamatan terhadap suatu objek, kejadian, atau fenomena tertentu. Kegiatan observasi dilakukan dengan terjun langsung atau melibatkan diri kedalam objek, peristiwa, dan fenomena yang diamati.

\subsection{Metode Pengolahan Data}

Tahapan pengolahan data dalam penelitian ini meliputi pengumpulan data, pengolahan data, serta visualisasi data. Data suhu udara serta suhu titik embun diolah lebih lanjut menjadi data kelembapan udara menggunakan persamaan (Abbott, 2003):

$$
H S=S P \text { Lanomali bulan ke }-i-S P L M M M \text { bulan } k e i
$$

Nilai $H S \leq 0^{\circ} \mathrm{C}$ menunjukkan pemutihan karang tidak terjadi(kondisi aman)

Nilai HS antara 0 dan $1{ }^{\circ} \mathrm{C}$ menunjukkan kondisi hati-hati

Nilai $H S \geq 1{ }^{\circ} \mathrm{C}$ menunjukkan kondisi siaga

Data dalam penelitian ini selanjutnya dicari nilai rata-rata bulanannya dari tahun 2006 2015. Rumus Excel yang digunakan untuk mencari rata rata Hotspot sebagai berikut :

$$
\begin{gathered}
=\operatorname{IF}(\operatorname{COUNTIF}(C 2: L 2, "<0 ")>5, \operatorname{AVERAGEIF}(C 2: L 2, "<0 "), \operatorname{AVERAGEIF}(C 2: L 2, " \\
>0 "))
\end{gathered}
$$

\section{HASIL DAN PEMBAHASAN}

\subsection{Identifikasi Wilayah yang Berpotensi Terjadi Pemutihan Karang}

Suhu permukaan laut salah satu faktor penentuan daerah yang berpotensi terjadi pemutihan karang. Daerah yang terpilih berdasarkan persyaratan kondisi iklim untuk pemutihan karang seperti yang terlihat pada Gambar 4.9 berikut. 


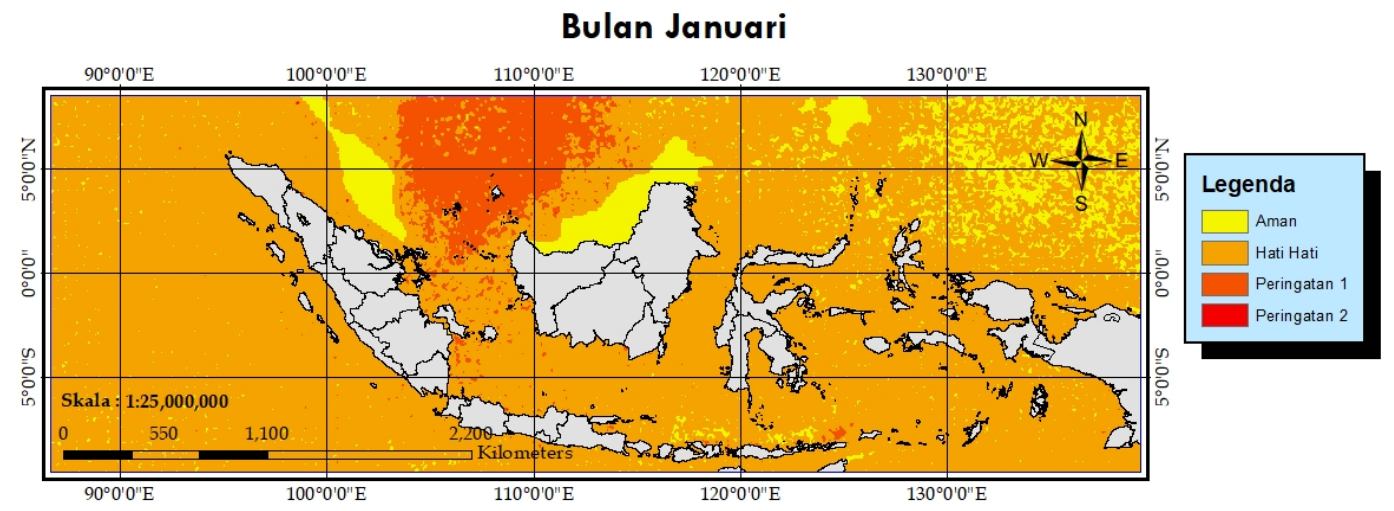

Gambar 4.1 Peta Wilayah Potensi Terjadi Pemutihan Karang Bulan Januari

Sebaran bulan Januari dapat diketahui bahwa wilayah yang berpotensi peringatan 1 (HS > 1) terjadi pemutihan karang berada di perairan Natuna terutama Laut Natuna Utara, pesisir bagian timur laut tanjung pinang serta pesisir timur laut NTT.

Bulan Februari

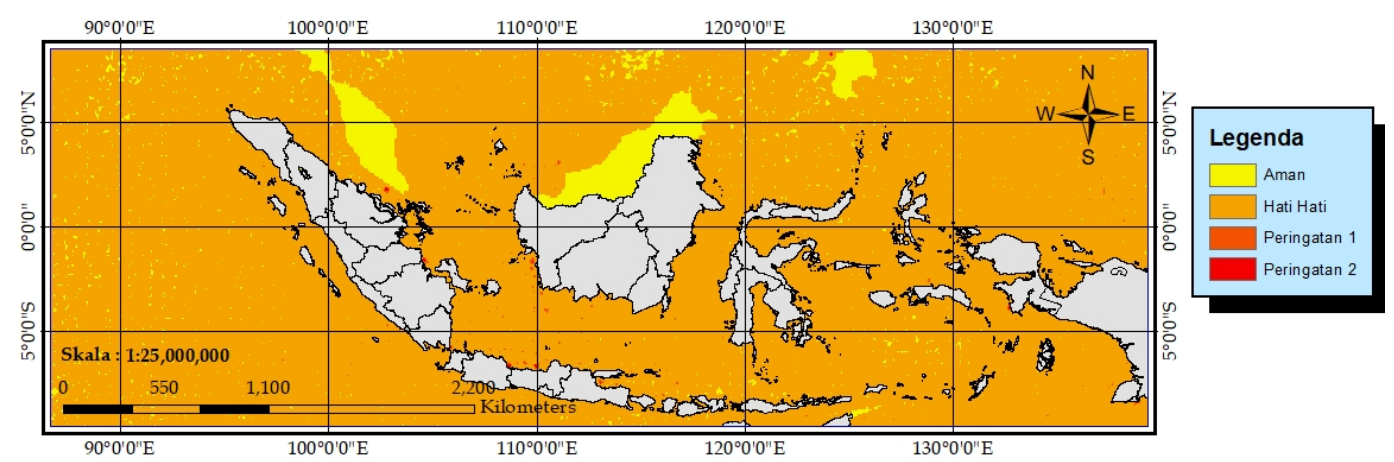

Gambar 4.2 Peta Wilayah Potensi Terjadi Pemutihan Karang Bulan Februari

Sebaran bulan Februari dapat diketahui bawah secara umum bersifat hati hati $(0<\mathrm{HS}<1)$ namun terdapat wilayah yang berpotensi terjadi pemutihan karang bersifat peringatan 1 (HS $>1$ ) yaitu wilayah perairan utaran Pekanbaru dan perairan barat laut Kalimantan Barat.

\section{Bulan Maret}

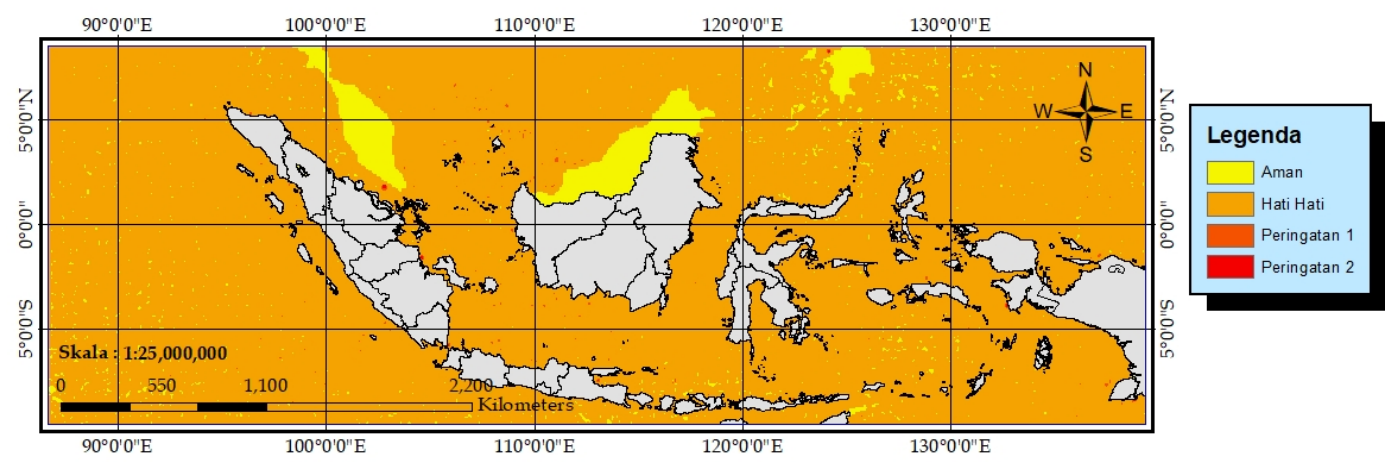

Gambar 4.3 Peta Wilayah Potensi Terjadi Pemutihan Karang Bulan Maret 
Sebaran bulan Maret dapat diketahui bawah secara umum bersifat hati hati $(0<\mathrm{HS}<1)$ namun terdapat wilayah yang berpotensi terjadi pemutihan karang bersifat peringatan 1 (HS $>1$ ) yaitu wilayah perairan utaran Pekanbaru.

Bulan April

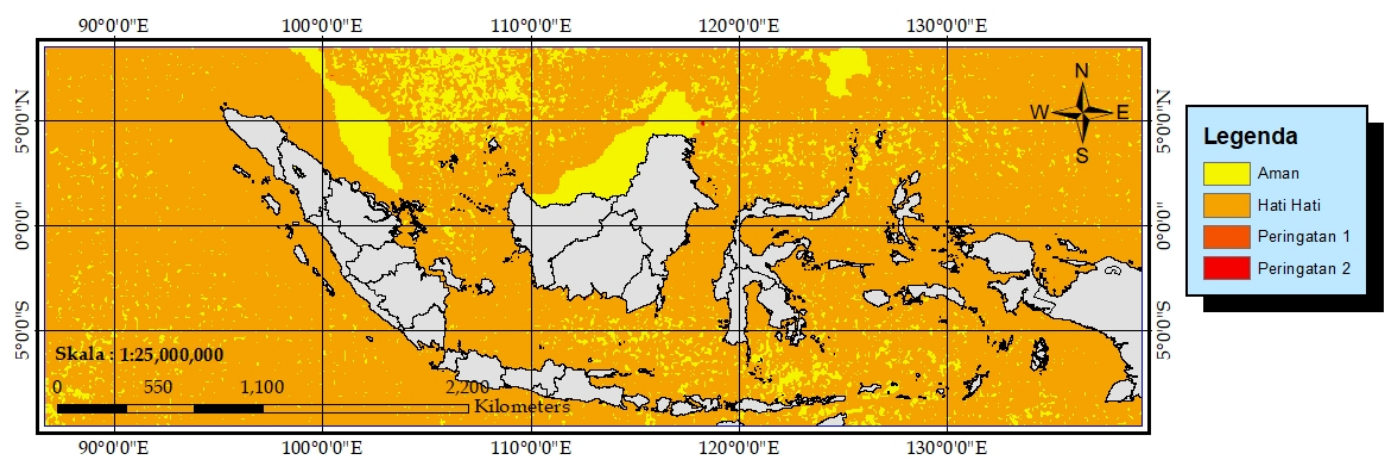

Gambar 4.4 Peta Wilayah Potensi Terjadi Pemutihan Karang Bulan April

Sebaran bulan April dapat diketahui bawah secara umum bersifat hati hati $(0<\mathrm{HS}<1)$ di seluruh perairan Indonesia

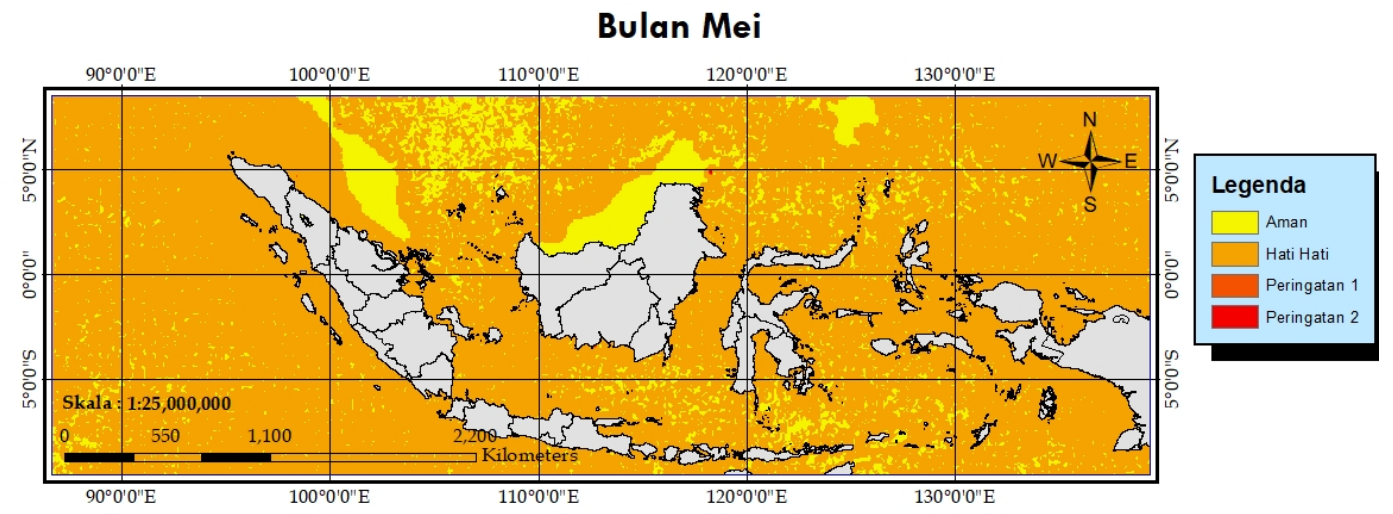

Gambar 4.5 Peta Wilayah Potensi Terjadi Pemutihan Karang Bulan Mei

Sebaran bulan Mei dapat diketahui bawah secara umum bersifat hati hati $(0<\mathrm{HS}<1)$ di seluruh perairan Indonesia

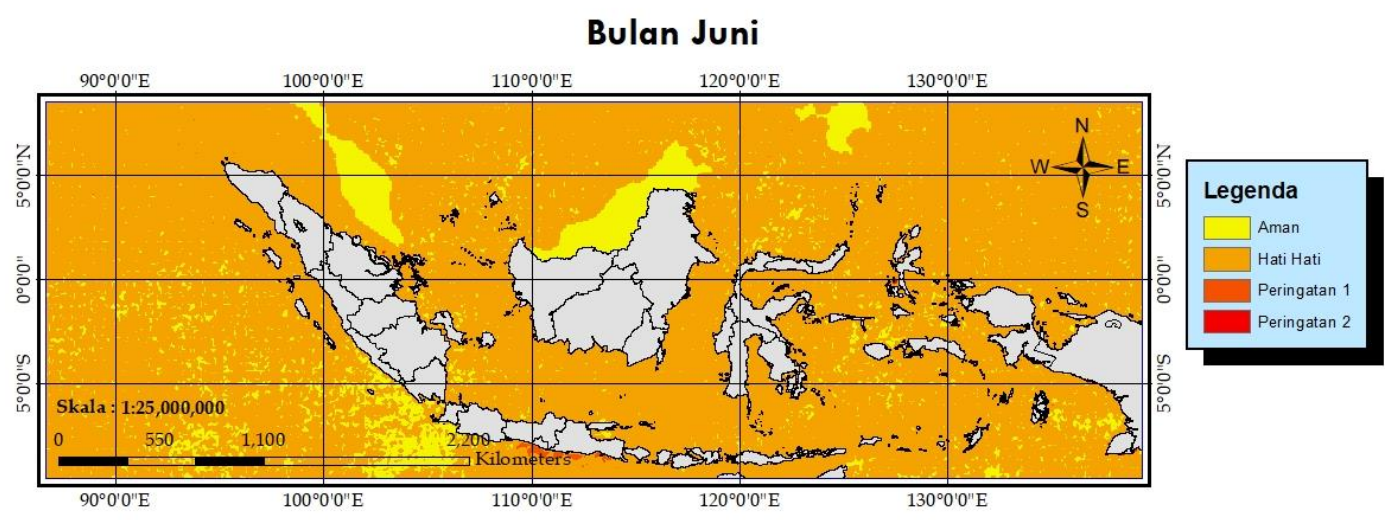

Gambar 4.6 Peta Wilayah Potensi Terjadi Pemutihan Karang Bulan Juni 
Sebaran bulan Juni dapat diketahui bawah secara umum bersifat hati hati $(0<\mathrm{HS}<1)$ namun terdapat wilayah yang berpotensi terjadi pemutihan karang bersifat peringatan 1 (HS $>1)$ yaitu berada di perairan selatan Yogyakarta.

\section{Bulan Juli}

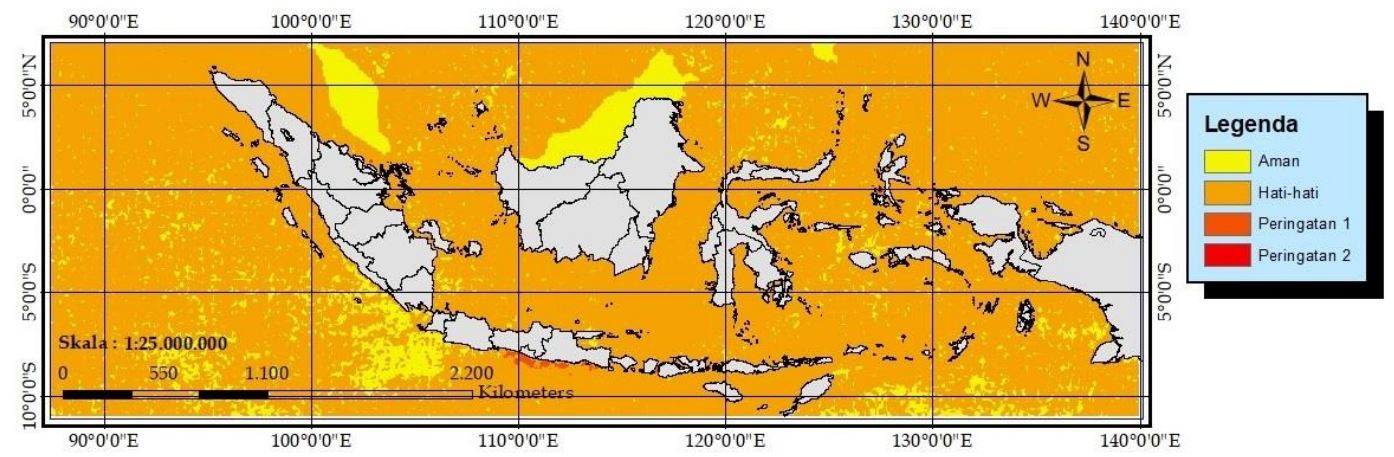

Gambar 4.7 Peta Wilayah Potensi Terjadi Pemutihan Karang Bulan Juli

Sebaran bulan Juli dapat diketahui bawah secara umum bersifat hati hati $(0<\mathrm{HS}<1)$ namun terdapat wilayah yang berpotensi terjadi pemutihan karang bersifat peringatan 1 (HS $>1)$ yaitu berada di perairan selatan Yogyakarta.

\section{Bulan Agustus}

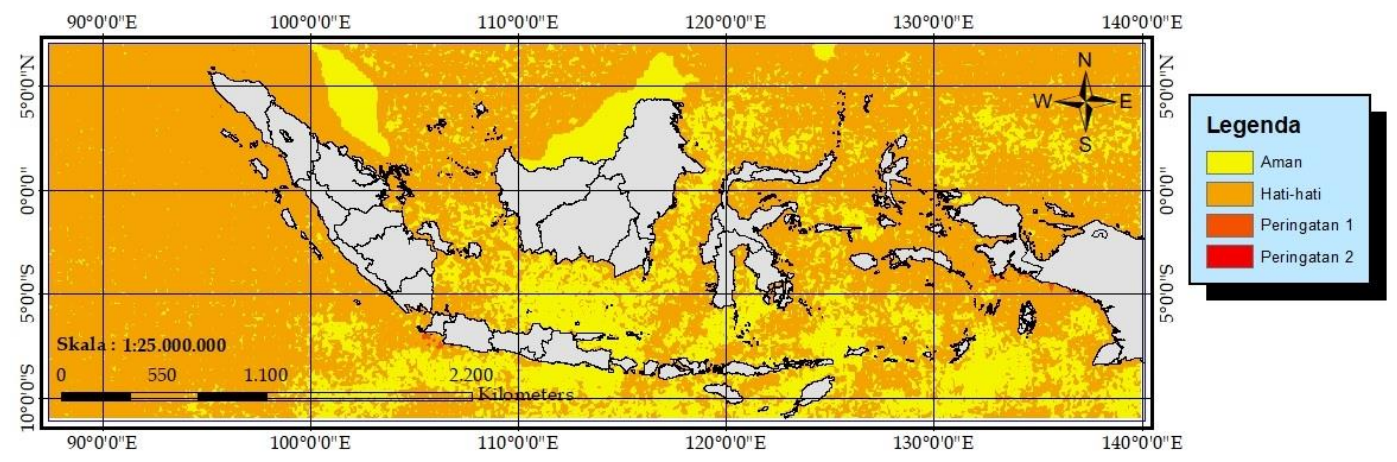

Gambar 4.8 Peta Wilayah Potensi Terjadi Pemutihan Karang Bulan Agustus

Sebaran bulan Agustus dapat diketahui bawah secara umum bersifat hati hati $(0<\mathrm{HS}<1)$ namun terdapat wilayah yang berpotensi terjadi pemutihan karang bersifat peringatan 1 (HS $>1$ ) yaitu berada di perairan selatan Banten. 


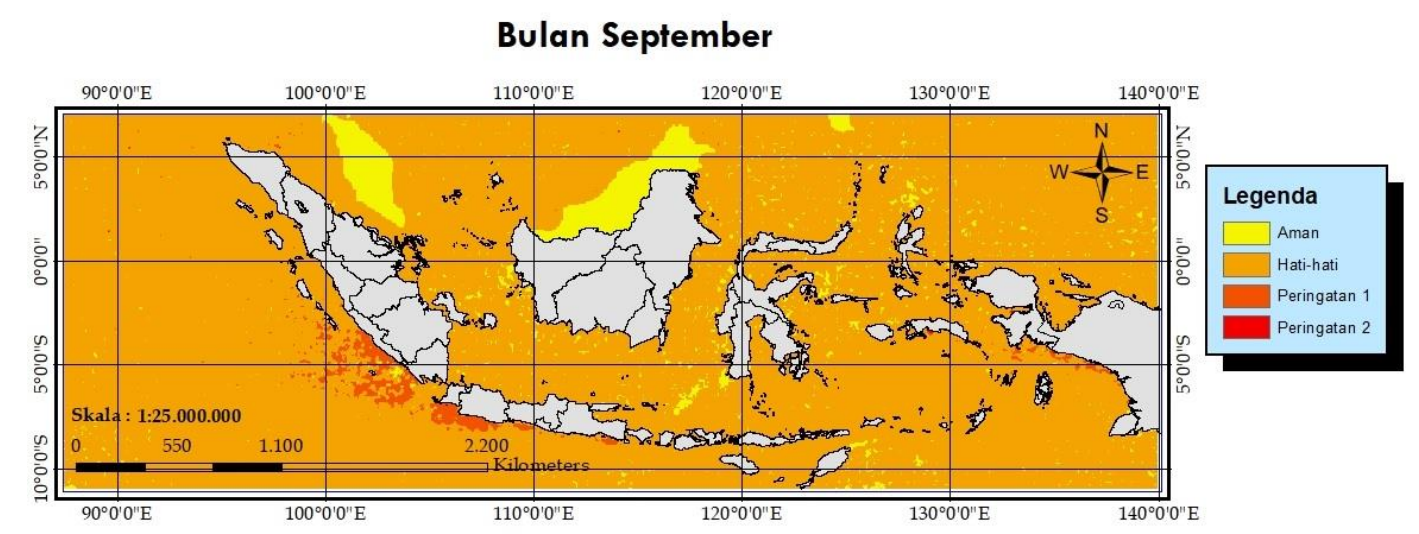

Gambar 4.9 Peta Wilayah Potensi Terjadi Pemutihan Karang Bulan September

Sebaran bulan September dapat diketahui bawah secara umum bersifat hati hati $(0<\mathrm{HS}<1)$ namun terdapat wilayah yang berpotensi terjadi pemutihan karang bersifat peringatan 1 (HS $>1$ ) yaitu wilayah perairan timur Jawa Timur ,perairan timur Jawa Barat, perairan barat laut Lampung, perairan barat Bengkulu serta perairan utara hingga timur laut kepulauan Aru

\section{Bulan Oktober}

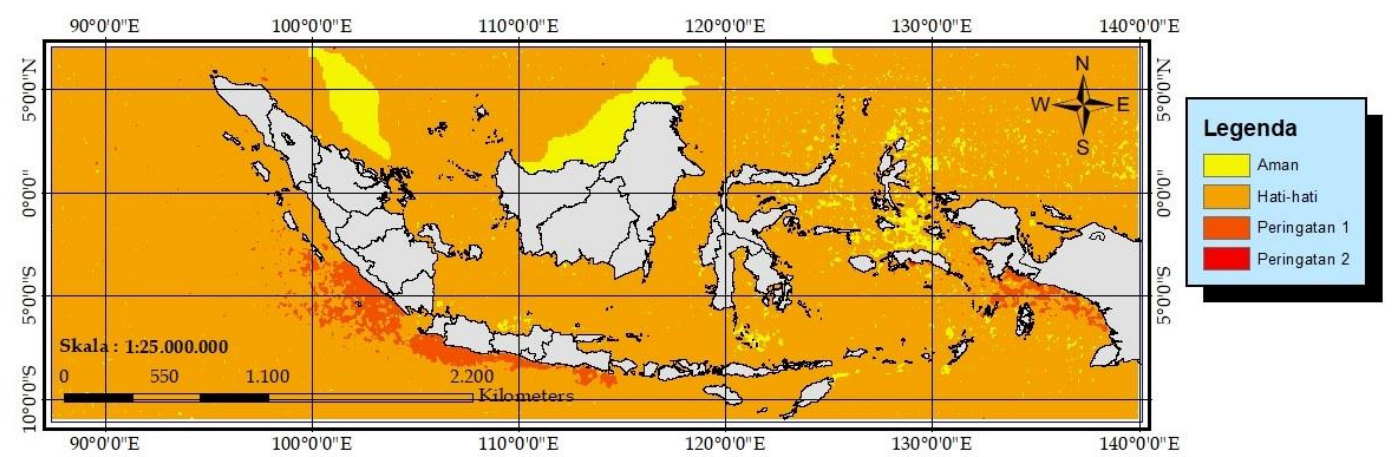

Gambar 4.10 Peta Wilayah Potensi Terjadi Pemutihan Karang Bulan Oktober

Sebaran bulan Oktober dapat diketahui bawah secara umum bersifat hati hati $(0<\mathrm{HS}<1)$ namun terdapat wilayah yang berpotensi terjadi pemutihan karang bersifat peringatan 1 (HS $>1$ ) yaitu seluruh wilayah perairan selatan Pulau Jawa, perairan barat laut Lampung, perairan barat Bengkulu serta perairan barat daya hingga timur laut kepulauan Aru 


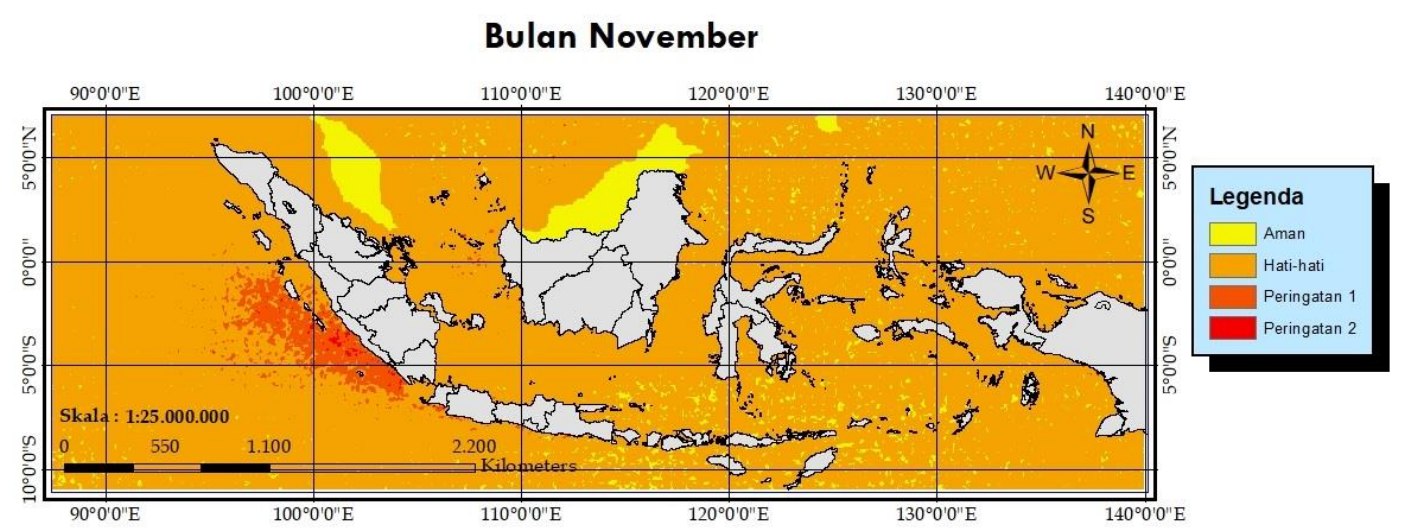

Gambar 4.11 Peta Wilayah Potensi Terjadi Pemutihan Karang Bulan November

Sebaran bulan November dapat diketahui bawah secara umum bersifat hati hati $(0<\mathrm{HS}<1)$ namun terdapat wilayah yang berpotensi terjadi pemutihan karang bersifat peringatan 1 (HS $>1$ ) yaitu perairan barat lampung, perairan barat Bengkulu, perairan barat jamb, perairan barat padang serta perairan barat Kalimantan barat

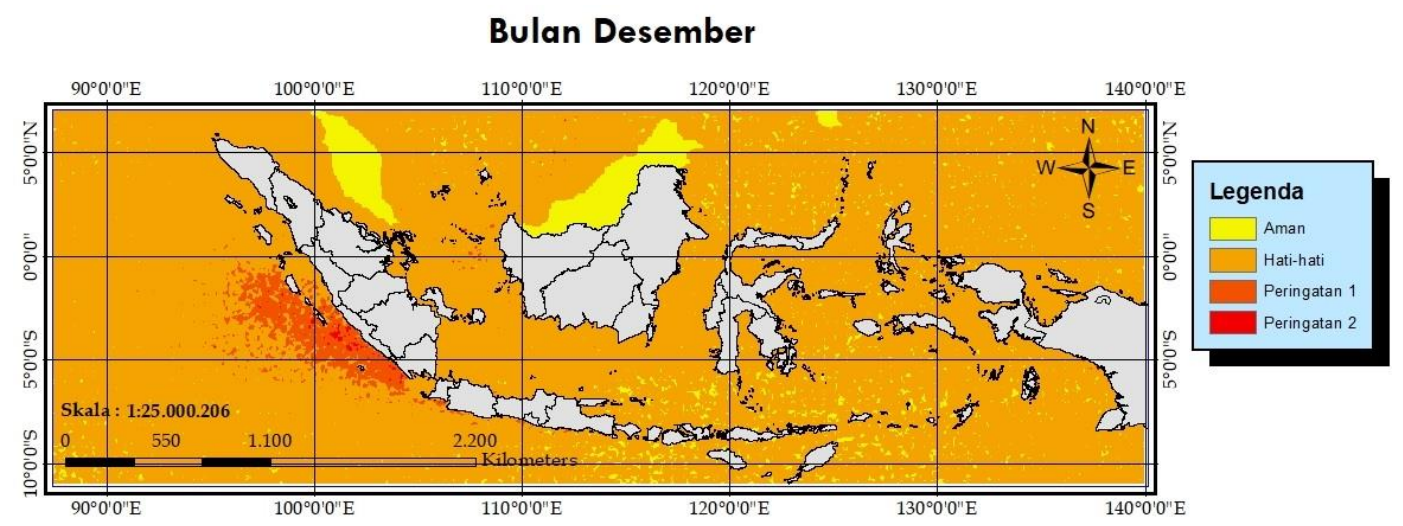

Gambar 4.12 Peta Wilayah Potensi Terjadi Pemutihan Karang Bulan Desember

Sebaran bulan November dapat diketahui bawah secara umum bersifat hati hati $(0<\mathrm{HS}<1)$ namun terdapat wilayah yang berpotensi terjadi pemutihan karang bersifat peringatan 1 (HS $>1$ ) yaitu perairan barat lampung, perairan barat Bengkulu, perairan barat jamb, perairan barat padang serta perairan barat Kalimantan barat

\section{PENUTUP}

\subsection{Kesimpulan}

Berdasarkan hasil penelitian, dapat diketahui bahwa wilayah yang berpotensi menjadi pemutihan karang di perairan Indonesia cukup beravariasi. Secara umum meliputi meliputi pesisir utara dari Provinsi Banten, DKI Jakarta, Jawa Barat, Jawa Tengah, Jawa Timur, pesisir barat laut Lampung, Bengkulu, pesisir barat laut dari Pulau Papua, dan perairan Natuna Utara. Hasil penelitian juga menunjukkan bahwa suhu permukaan laut di perairan Indonesia 
cukup mempengaruhi pemutihan karang. Namun masih ada beberapa daerah yang belum mencapai kriteria tersebut, akibat adanya faktor lain yang mempengaruhi pemutihan karang yaitu kondisi atmosfer lokal setempat terkait unsur kelembapan udara, curah hujan, pasang surut, arus dan kandungan $\mathrm{CO}_{2}$ di laut.

\subsection{Saran}

Dengan adanya informasi tentang wilayah yang terjadi pemutihan karang diharapkan pemerintah lebih peduli dan memiliki inovatif untuk membuat kawasan pelestarian terumbu karang agar keindahan dan kehidupan terumbu karang tetap terjaga. Instansi pemerintah yang dimaksud dalam hal ini meliputi Kementrian Kelautan dan Perikanan (KKP) yang memiliki tugas dan kewenangan di bidang produksi garam di Indonesia, Kementrian Pariwisata dan Badan Meteorologi Klimatologi dan Geofisika (BMKG) yang bertanggung jawab atas segala informasi iklim dan cuaca Dengan melestarikan terumbu karang di perairan Indonesia artinya kita juga telah menjaga objek wisata di Indonesia. Terjaganya keindahan objek wisata Indonesia tentunya dapat meningkat jumlah wisatawan nasional maupun internasional.

\section{DAFTAR PUSTAKA}

Agus, Samsul B. dan M, Anggi Afif. 2010. Modul Pelatihan PPIKP Dasar-Dasar Pengenalan GIS. Bogor : Institut Pertanian Bogor

Lubis, Atika dan Yosi Mira. 2011. Kondisi Meteorologi Maritim dan Oseanografi di Perairan Sekitar Pulau Kotok, Kepulauan Seribu : April 2011. Bandung: Meteorologi, ITB.

Pedoman LKTIN Geo-Smart Competition 2017

Tim Tekknis Nasional. 2007. Modul Pelatihan Arc GIS Dasar.

Priyatmoko, Rakhman. 2016. Tingkat Kesadaran Pramuwisata Terhadap Branding Wonderful Indonesia Dan Pesona Indonesia: Strategi Pemasaran Destinasi Pariwisata.Yogyakarta

Wahyu ,dkk. 2013. Segitiga Terumbu Karang (coral triangel)". Malang : Ilmu Kelautan, Universitas Brawijaya.

Wouthuyzen, Sam. 2009. Pengungkapan Kejadian Pemutihan Karang Tahun 2010 Melalui Analisis Suhu Permukaan Laut . Jakarta: LIPI. 